\title{
Del imperialismo al imperio
}

\author{
El fármaco democrático y otros \\ factores de incertidumbre \\ en las relaciones E.U.-Latinoamérica
}

DAVID VALENCIA*

\section{RESUMEN}

En este artículo se discute al ámbito político de las relaciones entre E.U. y Latinoamérica, para repensar las tensiones normativas entre la esfera interna de cada país y el ambiente político internacional. Nociones como co-evolución asimétrica servirán para desmitificar la idea de influencias unilaterales por parte de una potencia como Estados Unidos sobre los países sometidos a su esfera de influencia económica y cultural.

Se trataría, entonces, de un entretejimiento estratégico, donde tanto Estados Unidos como Latinoamérica se presuponen recíprocamente, co-evolucionan de manera conjunta, se interpenetran de tal suerte que el sistema se hace impredecible, de allí que las medidas adoptadas por E.U. surtan un efecto sorpresivo o muchas veces contrario al que se esperaba.

\section{PALABRAS CLAVES}

Aldea Global, Deslocalización, interdependencia.

\section{ABSTRACT}

In this article is discussed the political atmosphere in the relationships between the United States and Latinamerica, to think over again the normative tensions between each country's intern sphere and

* Docente de la Facultad de Derecho de la Universidad Santo Tomás de Bogotá. 
the international political atmosphere. Notions such as asimetric co-evolution will be useful to cast down the myth of unilateral influences that come from a potency as the United States over the countries subjected to their economical and cultural influence's sphere.

In that case it would be about a strategic interweaving, where the United States and Latinamerica presupose each other reciprocally, they co-evolve together, they interpenetrate in such a way that the system becomes unstable, from there that the measures adopted by the United States cause a surprising effect or many times opposite at the one that was expected.

\section{KEY WORDS}

Global Village, Delocation, interdependence.

\section{EL CONCEPTO DE MINDSET ${ }^{1}$ Y LAS PRESUPOSICIONES TRADICIONALES}

La cronología de Peter $\mathrm{H}$. Smith² sobre las relaciones entre Estados Unidos y Latinoamérica permite adelantar una hipótesis acerca de los patrones de orden emergentes en este campo.

Resulta muy útil analizar el concepto de mindset para descubrir no solamente los prejuicios de las naciones en sus relaciones recíprocas, sino sobretodo para desnudar los prejuicios que habitan la mente del investigador. Es decir, habría no solamente que indagar por las preferencias y la racionalidad oculta en los actores del escenario internacional ${ }^{3}$, sino sobretodo indagar por la racionalidad (o irracionalidad) pre-consciente en la mente del investigador.

Interesa según este último enfoque desandar cómo el sujeto investigador hace su objeto de estudio, visibilizando la lógica de la práctica del investigador, cuál es la disposición de los hilos de la trama, la forma particular de tejer el relato histórico, los criterios de que dispone para juntar, agrupar los acontecimientos, saber cuáles son sus elementos de juicio, sus modelos analíticos, porque de esas elecciones pre-discursivas va a depender lo que pueda decir. Lo que se ve depende del lugar desde donde se mire, las conclusiones alcanzadas se logran según el armazón teórico aplicado al caso. El mismo caso es una resultante de los intereses y afinidades cognoscitivas del autor, del sujeto cuya intervención jamás podrá ser descartada de su obra, de la textura de sus apreciaciones.

En este sentido, nos preguntamos, por ejemplo, porqué le preocupa tanto a Peter Smith hallar regularidades, encontrar simetrías, desentrañar un orden oculto (why patterns?). La tendencia hacia el orden constituye un punto de partida determinante en el tipo de mirada que se aplique a los "acontecimientos"; aclarando por supuesto que no hay "acontecimientos" ni "hechos" naturales, son tales pero porque el historiador los ha seleccionado, juzgando un elemento pertinente de una maraña infinita de aproximaciones al pasado.

$1 \quad$ Mindset es un anglicismo usado para significar los esquemas de pensamiento, percepción y acción que sirven de criterios cognoscitivos básicos, así como sistemas de orientación de la praxis de las personas.

2 SMITH, Peter. Talons of the Eagle, dynamics of U.S.-Latin American Relations, Oxford University Press, New York, 1996.

3 "For implementation states depend upon subjective perceptions, especially mutual perceptions of mayor powers, as well as upon objective realities". SMITH, Peter. Talons... Op. Cit., p. 5. 
Con la consideración anterior resulta interesante contrastar las diferentes escuelas que se han ocupado de las relaciones internacionales con un enfoque como el que recientemente han propuesto Hardt y Negri, en su ya clásica obra Imperio.

La escuela realista había partido de un modelo convencional, donde la pretensión descriptiva determinaba que grupos bien acotados (Estadosnación) luchaban por el predominio político, lo cual generaba el problema central: la guerra, la inestabilidad, el conflicto. Un modelo como el Global Society, con una igual pretensión descriptiva, involucra nuevos aspectos de análisis, recurriendo también a las formas interdependientes que desarrollan los grupos en disputa, que ya no solamente son acotados geográficamente, sino que incluyen actores como las ONG o incluso Ios individuos particulares. En este segundo modelo confluyen disciplinas como las ciencias naturales, lo cual expande la percepción exclusivamente política, histórica o económica.

El capitalismo como sistema-mundo va a ser, en cambio, el foco del interés de un modelo marxista como el usado por la teoría de la dependencia, el cual pone en juego toda la metodología de análisis marxista para entender porqué unas naciones se han hecho ricas y por el contrario otras viven en una pobreza lamentable.

Todos estos enfoques parten de una realidad exterior que hay que describir, incluso bajo la crítica marxista; el problema del imperialismo está delimitado por la naturalización de las observaciones realizadas por los investigadores. Se toman esos datos como incuestionables.
Para ejemplificar lo anterior me permitiré citar los tres modelos imperialistas que describe Peter Smith en la obra a la que se ha hecho referencia:

El primero consiste en una anexión efectiva de los territorios colonizados ${ }^{4}$. La segunda opción consiste en considerar las colonias bajo un status especial ${ }^{5}$, y por último está la alternativa de consolidar una esfera de influencia sin una intervención militar directa ${ }^{6}$.

Hago las citas anteriores porque desarrollando este aspecto se apreciará la postura central que anima la elaboración de éste ensayo. En las tres hipótesis anteriores, así como en los tres modelos sobre las relaciones internacionales, se parte del supuesto de unas coordenadas fijas de inteligibilidad; es decir, las maneras en que se presenta el imperialismo (anexión efectiva de territorio, la forma del protectorado y la de la esfera de interés) trabajan con la premisa de un espacio asignable, de una dominación que puede cuantificarse, encontrase en el mapa, calcularse con exactitud, incluso en la más difusa alternativa de la "esfera de interés" se pueden discernir los contornos de dicha esfera. Su determinación es asunto sencillo.

No ocurre así con el enfoque que manejan Hardt y Negri en Imperio ${ }^{7}$, lo seductor de este libro es que se libera de esas constricciones cuadriculantes, allí se plantea que la vieja época del imperialismo en su triple presentación ha cambiado radicalmente. La soberanía del Imperio es ahora descentrada y desterritorializada. Deslocalizada respecto a marcos de referencia.

\footnotetext{
$4 \quad$ Leading to effective enlargement of the boundaries of the nation state. SMITH, Op. Cit., p. 17.

5 Through this method, imperial dominions attained special status as subordinate appendages to the metropolitan nation and, usually, to its central government. Ibíd., p. 18.

6 "sphere of interest" over which an imperial power would exert de facto hegemony through informal means. Ibíd., p. 18.

7 HARDT, Michael y NEGRI, Antonio. Imperio. Paidós, Barcelona, 2001.
} 
Los límites son difusos y hoy en día, cuando el mundo entero ha caído bajo la influencia de un capitalismo completamente mundializado, ya no es posible distinguir con claridad territorios objeto de dominación y otros que no lo sean (la profecía de la aldea global de Marshall MacLuhan), así como tampoco es fácil ubicar un lugar de mando fijo, un sitio exacto desde donde se ejerce la hegemonía imperial.

Ahora bien, los tres modelos de comprensión de las relaciones internacionales (realismo, de la sociedad global y marxista) también son objeto de duda bajo las consideraciones antecedentes. La presuposición básica según la cual cualquier análisis en el plano internacional debe tratar de describir de la forma más exacta posible lo que ocurre en "la realidad" mundial, también caen bajo las observaciones que hacíamos hace un momento. Las intenciones descriptivas crean el objeto descrito, es por ello que más que indagar las motivaciones ulteriores de los agentes (los países, las naciones o incluso los imperios) vale la pena explorar la forma como tal "realidad" ha sido constituida. Lo cual no indica que se caiga en un relativismo a ultranza sino que las condiciones "materiales" van a ser tomadas como un resultado de procesos cognoscitivos donde la relaciones de jerarquía y mando posibilitan la emergencia o no de determinadas interpretaciones.

No es que el mundo objetivo no exista, por supuesto que hay condiciones de elaboración del conocimiento, pero es que éstas no son inalterables ni absolutas, constriñen, claro, pero su poder no deriva de ningún mundo verdadero o de una realidad ajena, sino de un conjunto de mecanismos opresivos que se articulan con dominios de discurso posibles.

La consecuencia de esa interacción es el mundo dado por cierto, garantizado por el mindset, que es un artilugio perfectamente histórico y no un sistema de enjuiciamiento neutral y desinteresado.

\section{EL FÁRMACON DEMOCRÁTICO, UNA TOXICOMANÍA DE VARIOS SIGLOS}

Por lo que acaba de ser expuesto, se muestra como muy relevante para éste análisis el tema del discurso democrático.

Asumimos la democracia como espacio retórico por excelencia, como una interjección de discursos politizados, como un poder sobre la naturaleza del poder, un gobierno sobre las formas de gobierno, una tecnología de poder específica (que domina su capacidad de dominar), un ensamblaje verbal, un entramado lingüístico, un cartograma de posibilidades discursivas, una deliberación sobre las reglas para deliberar, un remedio (en términos de Platón) un fármaco tanto para el corpus discursivo como para el corpus político, el llamado autogobierno del pueblo, donde confluyen paradójicamente las categorías de amo y esclavo, se autogestionan los propios esquemas operativos; en fin, la democracia como autoconciencia política no deja de ser una antinomia inquietante.

Estados Unidos ha racionalizado el ejercicio de su dominación hacia Latinoamérica según este evangelio: el fármaco democrático (es una droga: cura y mata a la vez, en ciertas dosis el medicamento salva la vida, en otras intoxica mortalmente).

El asunto del manifest destiny norteamericano está directamente implicado con ésta presunción democrática. E.U. desde su nacimiento se ha vanagloriado de poseer unas instituciones verdaderamente representativas, un sistema político tan bueno que incluso puede ser impuesto a la fuerza a los países que no han podido implementarlo. Pero como toda droga la democracia puede ser adictiva, puede generar hábito, dependencia, hacerse un vicio. Creo que esa es el panorama de las relaciones internacionales en la actualidad. 
Se podría leer el proceso de consolidación de la hegemonía norteamericana como un caso de toxicomanía severa. En un inicio la era imperial (imperialista) habría mostrado un incipiente potencial de abuso del discurso democrático ejemplificado por la doctrina Monroe (y asumido con más seriedad en el momento del corolario de Theodor Roosvelt a esta doctrina), luego de un período de uso de la fuerza (expansión territorial en México, toma de las colonias españolas y progresivo dominio del mar Caribe a través de la "diplomacia del dólar") vendría la "buena vecindad" a significar un cierto cambio en la lógica de sujeción.

Se suaviza, se dulcifica el veneno, se le agregan excipientes normalizando así unas relaciones sociales de producción inequitativas y explotadoras. Durante el período de la buena vecindad y luego del susto de la gran depresión, conjurado apenas por un Keynesianismo que dotaba al Estado de herramientas que garantizaran la demanda efectiva, e iniciara un cierto Estado de bienestar (sobretodo durante el Welfare State en Gran Bretaña y posteriormente en Europa), se logra una habituación a una lógica de la práctica capitalista.

En síntesis, ya no se trata tanto de una coacción directa, sino del ejercicio por parte de los Estados Unidos de una violencia indirecta, sutil, a través de la retórica del "no intervencionismo", produciendo una persuasión generalizada, una hegemonía naturalizada. Ha habido un pliegue, un giro en el estilo de la política exterior norteamericana, entendida ésta como praxis discursiva. Se ha disfrazado la coerción, pero evidentemente esto no significa que la relación de desigualdad desaparezca, o que la asimetría disminuya, nada de eso, con otros artificios las condiciones de explotación permanecen.

Se podría decir, siguiendo este orden de ideas, que a este período de dulcificación habría se- guido durante la guerra fría un recrudecimiento de las intervenciones violentas, o al menos un intervencionismo claramente imperialista; con el pretexto de la lucha anticomunista se habría endurecido el rostro antes amable de la administración de F. D. Roosvelt.

Si se sostiene que la gran depresión solamente fue definitivamente superada con la economía de guerra desplegada durante el segundo conflicto bélico mundial, es claro que ya para ese momento los Estados Unidos habían asumido el rol de superpotencia, a la vez que la Unión Soviética se había erigido como rival formidable. Era necesario, entonces, echar mano del fármaco democrático, que no es que hubiera desaparecido, solo había mutado su cara bajo la égida de los vecinos amigables.

La llamada doctrina Truman echaba por la borda la política de autodeterminación del momento anterior, ahora había que contener el comunismo a cualquier precio. Pero claro, considerando al "mundo libre" de los regímenes democráticos como el único sistema de organización política admisible, lo demás era brutalidad y caos. Por eso una vez más la democracia y sus instituciones "representativas" son asumidas como la salvación (la cura, el medicamento). Había que salvaguardarlas a como diera lugar.

En un análisis del discurso geopolítico resulta sobremanera intrigante las formas de simbolización del enemigo, del Otro. Como ocurre con el fenómeno del chivo expiatorio, se le carga con todas las características del mal, y una vez satanizado de esa manera se puede destruir sin compasión alguna. Se elabora semánticamente al antagonista; lo anterior operó de parte y parte entre los representantes del "mundo libre" y los integrantes del bloque comunista. En este juego verbal hay que observar que no creemos que los actores digan sus discursos (por ejemplo Eisenhower proponiendo un 
robustecimiento militar para poder defender a Latinoamérica del peligro del comunismo) sino que es el discurso el que los dice a ellos, los crea como personajes textuales, los hace, los performa. Eisenhower es dicho por ese discurso, al igual que la situación es dicha, tramada, puesta en verbo; el referente es textualmente armado, no al revés. La anterior digresión desde el punto de vista del análisis del discurso, claro, sería difícil decir lo mismo para un inmaculado e intocable "sentido común", o según una lógica racionalizante.

Pero es en el momento en que J, F. Kennedy asume el poder y habla de una alianza para el progreso cuando la alucinación inducida por el consumo descontrolado del fármaco democrático alcanza su mayor fuerza; los niveles de abuso ya son inmanejables, ahora no solo se pretende que el modelo democrático del Estado de derecho y de las formas participativas (con las paradojas que señalábamos) es el único válido, sino que se pretende hacérselo tomar a los países latinoamericanos.

Bajo la idea de un mágico "despegue" (take off) económico de éstos países si cumplían la receta que se les daba se hicieron inversiones que buscaban sacar del subdesarrollo a las naciones de centro y Suramérica, pero no por una filantropía intensivamente explotada por el presidente Kennedy, sino porque se pensó que frenando las condiciones de desigualdad se erradicarían las posibilidades de una revolución armada de corte socialista o comunista; lo anterior resultó ser un estruendoso fracaso.

Como siempre en estas historias de drogodependencia y toxicomanía extrema, el remedio resultó peor que la enfermedad; por extirpar al comunismo se potenció la creación de grupos subversivos que en el caso de Colombia aún continúan activos.
En vez de robustecer las libertades, éstas fueron severamente recortadas tras la ola de golpes de Estado que desnaturalizó completamente el anhelo de democratizar a Latinoamérica.

Ocurrió todo lo contrario, la democracia dejó de significar igualdad participativa y libertades ampliadas, para pasar a representar una desigualdad crónica de la mano de las mayores violaciones a los derechos humanos que se hubieran producido durante el siglo XX en la región.

En últimas se privilegió la estabilidad (incluso apoyando dictadores tiránicos pero anticomunistas) a la dinámica de las libertades públicas.

Pareciera como si Latinoamérica fuera una especie de mundo al revés (como Alicia Del otro lado del espejo -Through the Looking Glass-), donde todo sale al contrario de lo premeditado, las reformas sociales generan más inequidades, y los desesperados intentos por contener el avance del comunismo en la idea de un "efecto dominó" que cumplía el propósito de agrandar sicológicamente el problema, trajo como consecuencia que un líder no comunista como Fidel Castro, posteriormente a 1959, decidiera buscar apoyo en la Unión Soviética luego de un embargo económico indignante, y del fallido desembarco en Bahía Cochinos (lo que hizo fue exacerbar el nacionalismo y crear simpatías a favor de los cubanos).

\section{LA DOBLE CONTINGENCIA, LA INCERTI- DUMBRE Y LAS PARADOJAS}

Como hipótesis explicativa hay que considerar que las relaciones internacionales pueden ser entendidas como un sistema complejo, tal y como la interacción de un ser vivo con su medio; de tal modo, si es válido aplicar la metáfora, los países latinoamericanos serían como un individuo condicionado por su dinámica interna, pero 
aún más por un medio exterior (E.U.A.), cuyos estímulos son ineludibles y muchas veces catastróficos.

Las interpretaciones que hace el ser vivo de su medio no son la realidad misma (la política exterior norteamericana), sino que a pesar de ser condiciones urgentes y casi unilaterales, la forma de asumirlas dependerá de la idiosincrasia particular del organismo (en éste caso de la nación objeto de influjo).

Además, resulta innegable que los individuos también condicionan su medio ambiente, pueden lograr transformaciones sobre aquello que los transforma, modelar su entorno, diseñar el mundo en que viven, aunque por supuesto este proceso no sea tan evidente como el proceso contrario, se trata de algo más sutil, más arduo y que requiere una perspectiva temporal mucho más amplia.

Así, puede decirse que Latinoamérica también influye a los Estados Unidos, alterando las estrategias de dominación del "coloso del norte". Valgan como ejemplo los flujos migratorios que han hecho del castellano el primer idioma más hablado en Norteamérica después del Inglés. Y otro tanto respecto de la penetración cultural estadounidense, es avasallante pero no es absoluta. Hollywood ha contribuido a formar los sistemas de pensamiento, eso difícilmente podría negarse, pero también es cierto que la mirada latina, ciertas apropiaciones culturales (aborígenes por ejemplo) han hecho que se trate de una situación bilateral aunque ostensiblemente asimétrica.

Se trataría entonces, de un entretejimiento estratégico, donde tanto Estados Unidos como Latinoamérica se presuponen recíprocamente, coevolucionan de manera conjunta, se interpenetran de tal suerte que el sistema se hace impredecible; de allí que las medidas adop- tadas por E.U.A. surtan un efecto sorpresivo o muchas veces contrario al que se esperaba.

Pasa como con los seres vivos: si se patea una piedra es muy evidente que a través de un cálculo simple se podrá determinar la trayectoria y el destino final del objeto. Pero con un ser vivo no ocurre lo mismo, al patear un perro -para continuar con el símil- nunca podrá asegurarse con el cien por ciento de exactitud la respuesta del animal. Y con un ser humano las cosas se complican muchísimo más. Y todavía más en el caso de una colectividad con una magnitud como la de una nación; el cálculo se hace perfectamente indeterminado.

Por eso hablamos de un sistema de doble contingencia para caracterizar las relaciones Latinoamérica-Estados Unidos, cada uno de los elementos interactuantes parte de la contingencia de la reacción del otro; así el mecanicismo se muestra inútil e improcedente, otros esquemas analíticos son necesarios.

Por último, en la llamada era de la incertidumbre, y con el giro de la lucha anticomunista como eje discursivo a la guerra contra las drogas, apreciamos con más claridad la actitud viciosa de las prácticas geopolíticas en América.

Puede sostenerse que la contención del comunismo tenía un rival claro, localizado en Moscú y con unos límites geográficos estables, ahora no; haciendo eco de la hipótesis de Hardt y Negri reseñada en un inicio, podemos decir que esta incertidumbre está ligada a lo que acabamos de describir como doble contingencia, como indeterminación en la predicción de los resultados de un ser vivo adaptándose a su medio. La cruzada contra las drogas es una tentativa deslocalizada, aunque se pretende fumigar ciertas zonas de cultivo "ilícito", estos cultivos se desplazan, hoy están en Bolivia, mañana en Colombia, Brasil, etc.; permanentemente en movi- 
miento es muy difícil atacar certeramente, no hay ubicación exacta, los carteles de la droga se reconfiguran de tal suerte que no pueden circunscribirse a un único punto sedentario.

El enemigo ahora es nómada, procede a efectuar una mutación sin tregua, se encuentra en devenir (incluso los flujos monetarios generados con el tráfico de estupefacientes es muy difícil precisarlos, o incluso probar su procedencia ilegal).

Evidentemente esta serie de cambios no pueden explicarse sino en el contexto de la Nueva agenda económica. Expresiones como globalización (globalización de lo local y localización de lo global), desregulación, reificación del libre mercado, desnacionalización de la soberanía, transnacionalización monetaria y judicial, etc., constituyen un arpegio de conceptos sobre los cuales se inscribe esta dinámica internacional cada vez más alejada de las predeterminaciones tranquilizantes y los planes exhaustivos.

El debate final que puede plantearse es cómo tras la caída de un antagonista como la Unión Soviética, que no gratuitamente inaugura la época de las desterritorializaciones con la emblemática caída del muro de Berlín (como si las fronteras se tornaran inoperantes; el caso dramático de la World Wide Web, Internet, donde la deslocalización y la velocidad de flujo de la información -también los avances en telecomunicaciones- han hecho de las barreras antes intraspasables algo anacrónico frente a la realidad de una tecnosfera sin límites), pero simultáneamente la reaparición de brotes xenofóbicos o el recrudecimiento del ímpetu nacionalista, así como el endurecimiento de las legislaciones sobre migración y la serie de trabas que se han impuesto a los viajeros fruto de los controles contra el transporte de alcaloides hacen que las cosas sean perfectamente contradictorias.

La noción de Imperio de Hardt y Negri implica que ninguna nación puede autoproclamarse como líder preponderante en el concierto político internacional, pero con los recientes eventos del 11 de septiembre de 2001 y el consecuente aplastamiento del régimen Talibán en Afganistán la situación pareciera mostrar que los Estados Unidos prácticamente no tienen rivales en la lucha por la supremacía política, económica y militar a nivel mundial.

La doctrina Bush Jr., ha sido clara con relación al nuevo estatuto de seguridad nacional: invirtiendo la más elemental lógica, E.U.A. y la OTAN pueden "atacar preventivamente" aún sin que se configuren los elementos para hablar de una legítima defensa en el vocabulario del Derecho Internacional Público.

Éste tipo de actitud ha hecho que organismos multilaterales como la Unión Europea hayan manifestado su descontento contra lo que parece ser uno de los actos de mayor arrogancia en la historia de la humanidad. 